in the above patient's seizure disorder, and a change in life style was important in seizure control. Macdonald Critchley (1942) in his report of cases of musicogenic epilepsy considered emotion an important precipitant. (In Lennox WG. Epilepsy and Related Disorders. Boston, Little, Brown, 1960;p362). In his hagiographic obituary of Macdonald Critchley, who died Oct 15, 1997, aged 97, Robert J Joynt described him as "a reminder of the great heritage of our specialty and a vibrant contributor to it." (Arch Neurol Jan 1998;55:122).

\title{
LORAZEPAM-INDUCED NEONATAL SEIZURES
}

Two cases of lorazepam-induced neonatal seizures are reported from the University of Rochester, NY. Patient 1, a full-term male infant intubated for transient tachypnea was given lorazepam (Ativan), $0.1 \mathrm{mg} / \mathrm{kg}$ iv, for sedation. Within minutes, the infant developed clonic jerks of both legs and right arm, occurring in bursts of 1 to 3 min for 1 hour. A 24-hour EEG recorded 2 hours after movements resolved was normal. Patient 2 had necrotizing enterocolitis at 3 days of age and was treated briefly with antibiotics. A single dose of lorazepam, 0.1 $\mathrm{mg} / \mathrm{kg}$ iv, was given as a sedative for placement of a percutaneous intravenous catheter. Within $1 \mathrm{~min}$, intermittent clonic movements of all extremities were followed by flaccidity and pallor that lasted for $5 \mathrm{~min}$, and clonus recurred every 5 minutes for one half hour. Follow-up examinations at 12 months were normal in both infants. (Chess PR, D'Angio CT. Clonic movements following lorazepam administration in full-term infants. Arch Pediatr Adolesc Med Jan 1998;152:98-99). (Respond: Dr Patricia R Chess, Department of Pediatrics, University of Rochester, Rochester, NY 14642).

COMMENT. Myoclonus associated with lorazepam therapy in premature neonates is a well known side effect. This appears to be the first report of seizurelike activity following lorazepam injection in otherwise neurologically normal, full-term infants. Additional etiologic factors considered included the propylene glycol adjuvant in the injection and the rate of administration.

\section{VIGABATRIN-INDUCED VISUAL FIELD DEFECTS}

A drug surveillance database at Hoechst Marion Roussel, manufacturers of vigabatrin, identified 92 cases of symptomatic visual field defects associated with vigabatrin (usually as add-on therapy) between 1990 and 1997. Two further asymptomatic cases have been identified in patients treated at the Prince of Wales Hospital and University of Sydney, Australia. Patient 1, a 21-year-old man with complex partial seizures had received carbamazepine for 12 years and vigabatrin $2 \mathrm{~g} /$ day for three years. Clinical visual field testing was normal, but Goldman perimetry showed bilateral nasal field defects and some superior peripheral field constriction. Electroretinography was also abnormal, showing reduced $b$ wave amplitude. Patient 2, a 36-year-old woman with tonic-clonic seizures treated with valproate and carbamazepine for 12 years, followed by carbamazepine and vigabatrin $2 \mathrm{~g}$ /day for two years, had questionable defects on clinical visual field testing and definite peripheral binasal field loss on Humphrey perimetry. Electroretinography showed reduction in $\mathrm{b}$ wave amplitudes in nasal fields. (Mackenzie R, Klistorner A. Severe persistent visual field constriction associated with vigabatrin. Asymptomatic as well as symptomatic defects occur with vigabatrin. BMI Jan 17, 1998;316:232-233). (Respond: Dr Rod Mackenzie, Director, Comprehensive Epilepsy Service, Prince of Wales Hospital, Sydney, Australia).

COMMENT. Vigabatrin antiepileptic therapy poses the risk of visual field damage that may be persistent. The number of symptomatic cases identified could 